\title{
Using the capabilities of artificial intelligence in the development of reflection skills
}

\author{
Polina Vysotskaya $^{1}$, Svetlana Zabelina ${ }^{1,{ }^{*}}$, Julia Kuleshova $^{1}$, Irina Pinchuk $^{1}$ \\ ${ }^{1}$ Moscow State Region University, 10A, Radio str., 105005, Moscow, Russia
}

\begin{abstract}
The problems of developing of soft skills of people involved in educational activities are examined, their composition in the field of education is revealed. Special attention is paid to the formation of reflective skills using the capabilities of artificial intelligence, in particular Chatbots. A technique has been developed for implementing the reflective management of the student's intellectual activity in the Chatbots system. Case scenaries are proposed that immerse the user in the problem space of the educational situation. The effectiveness of using the capabilities of artificial intelligence in the formation of reflective skill is proved.
\end{abstract}

\section{Introduction}

A feature of higher professional education in Russia is its inconsistency with the pace of changes in the country's economic sphere. Current trends require lifelong learning from a person, according to studies conducted by the Organization for Economic Cooperation and Development (OECD) [12]. Russian education system is traditionally more attention and efforts are paid to the formation of hard skills. However, modern realities have shifted the focus from hard skills to soft skills, which should entail a widespread reorganization of the training process for future specialists. Note that in this transformation process, it would be logical to use the accumulated experience that was effective in the successful formation of hard skills.

Modern scientific research does not reveal an unambiguous disclosure of the content of concepts denoting the supra-professional competencies of a specialist, in particular: "soft skills", "universal competencies", "meta-subject skills". For example, in the Oxford Dictionary, "soft skills" or soft skills are defined as integrative personal qualities of a person that determine the possibility of effective and harmonious interaction with other people [3].

Domestic researchers A.I. Ivonina, O.L. Chulanova and Yu.M. Davletshina introduced an integrated definition of soft skills, noting, that "this is a social and labor characteristic of a body of knowledge, skills, and motivational characteristics of an employee in the field of interaction between people, the ability to competently manage one's time, the ability to persuade, negotiate, leadership, emotional intelligence, with the emergence necessary for successful work and appropriate the requirements of the position and the strategic goals of the organization, this is a characteristic of potential quality that allows us to describe almost

* Corresponding author: zabelina_sb@mail.ru 
all the elements of staff readiness to effective work in a given situation at the workplace [4]. A.V. Vetkina divides professional skills into two groups: hard skills skills in the field of formalized professional base; soft skills less formalized skills needed in any profession [2]. The authors of the international project "Key competencies and new literacy" propose using the term "universal competencies", which denotes the ability of a specialist to effectively mobilize his knowledge and skills to solve problems in new non-standard situations. The developers emphasize that the universality of competencies reflects such characteristics as mass character (necessary for all and unlimited by any particular field of activity [8]. In our study, we used the concept of soft skills. Currently, in domestic science, many researchers and university teachers, in particular A.I. Ivonina, O.L. Chulanova, L.V. Chernetsova, A.V. Vetkina et al. T.A. Yarkova, I.I. Cherkasova, A.S. Patlina, E.D. Popova, regarding the problems of the formation and development of soft skills in the professional pedagogical sphere.The participants of the World Economic Forum in Davos (Switzerland) in 2016 highlighted the basic soft skills needed by a person of the 21 st century for successful professional activities and in everyday life. These skills are a set of common competencies for various types of activities and include some characteristic features of intellectual activity, managing one's own activity, emotional behavior and constructive cooperation with other people [9]. We believe that the problems of developing soft skills in people engaged in pedagogical activities deserve close attention, since educators are called upon to form appropriate skills in the younger generation. T.A. Yarkova and I.I. Cherkasov rightly noted that since the profession of a teacher is public, the skills of self-presentation are especially significant; the ability to build relationships with participants in the educational process; ability and willingness to solve creative problems; show leadership [11].

One of the criteria for assessing the success of mastering hard skills is considered to be IQ, while soft skills require EQ (assessment of emotional intelligence).

The importance of soft skills is growing exponentially due to the fact that the areas for which we train future specialists are changing so dynamically that we may not yet know the competencies that they will need in the process, but we can help strategically shape important professional skills.

Highlight the most significant soft skills in the field of education:

Table 1. Soft skills in education.

\begin{tabular}{|l|l|}
\hline \multicolumn{2}{|c|}{ Soft skills } \\
\hline Communicative & - the ability to listen; \\
& - persuasion and argumentation; \\
& - Negotiation; \\
& - producing a presentation; \\
& - self-presentation; \\
& - public performance; \\
& - teamwork; \\
& - focus on results; \\
& - business letter; \\
& - taking into account the interests of participants in the educational \\
& process \\
\hline Reflective & - management of emotions; \\
& - stress resistance; \\
& - management of their own development; \\
& - planning and goal setting; \\
& - self-organization; \\
& - energy, enthusiasm, initiative, perseverance; \\
& - reflection; \\
& - use of feedback \\
\hline - systemic thinking;
\end{tabular}




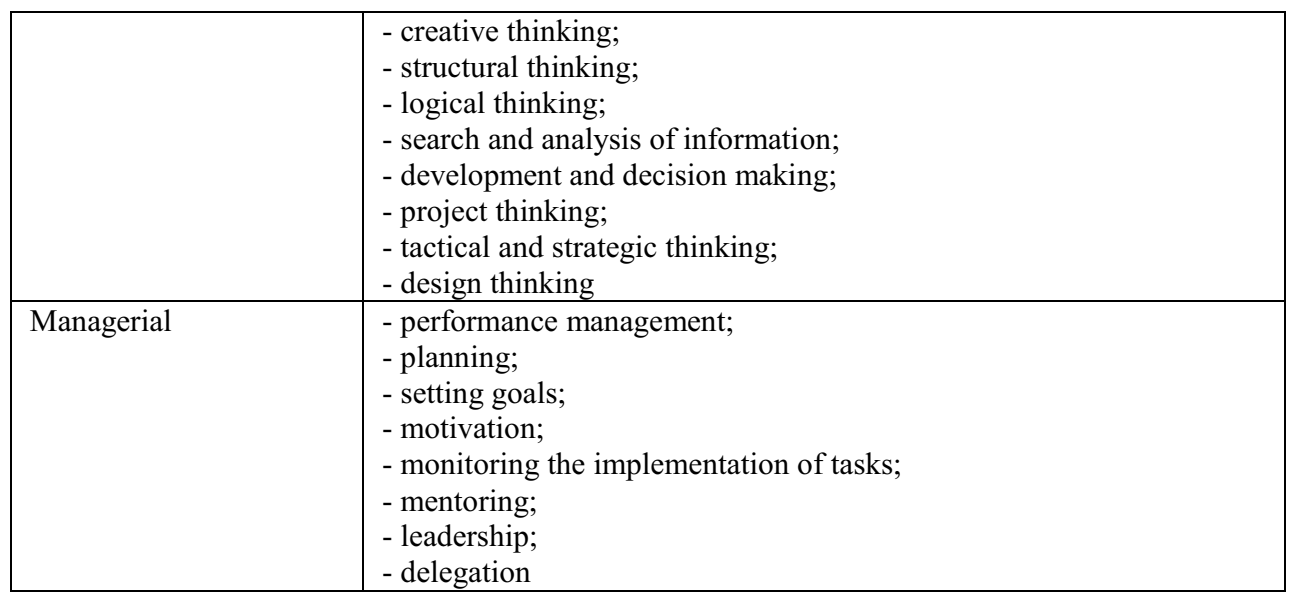

We pay attention to systematic reflection: as a self-generated skill, and the fact that it is an integral part of almost all soft skills. This fact indicates that the intellectual activity of person is not limited to the formation of models of the surrounding reality in his mind. Reflection gives rise to the subject's idea or judgment about the image of reality present in his mind, which implies an assessment of both the verbal-logical and emotional properties and manifestations of the models created in the imagination. This critical doubt does not in any way impede the consistent implementation of effective, goal-oriented actions. Therefore, there is an assumption that reflection as a skill can be formed by artificial intelligence, the task of which is to model cognitive processes. The research problem was the search for tools of artificial intelligence systems for the formation of reflection skills and testing the effectiveness of their impact on the subject of intellectual activity.

\section{Materials and Methods}

To solve the problem, we identified the main signs of intelligence, which identified expert systems as intelligent, having analyzed the history of the development of the theory of artificial intelligence, clarified the concept of reflexive control of the intellectual activity of the knowing subject.

Reflexive management of the intellectual activity of a knowing subject is the assimilation of information that affects his image of reality, the structure of ideas about cognition, or the volume and content of knowledge. Reflexive management of human intellectual activity is carried out on the basis of two interconnected resources: activity and intellectual. After each activity course of an individual related to the study of the educational situation, a response follows, generated by the thinking of the cognizing subject and, as a result, translates the initial actions into an increment of knowledge in a specific educational field. Figuratively, this process can be represented as a system of mirrors reflected in each other [6]. The relationship between the intellectual activity of the subject and the educational situation in which it is located is provided by two dependencies: the perception and study of the problematic educational space as a cognitive function, the impact on the situation of inferences adopted by the subject as an acting function. We came to the conclusion that in reflexive control, a transition is necessary from the situation to the problem space, combining the conditions for the existence of the problem, through its reflexive perception, which has the properties of systematicity, selectivity, productivity. We performed the modeling of a multifaceted problem space or the set of corresponding subspaces in a specific educational field using the Chatbots system of artificial intelligence. 
Chatbots are artificial intelligence systems with which users interact through the text proposed for study. Human interaction is modeled similar to the experience of using Apple Siri or Amazon's Alexa. In an interview with The Verge, Bill Gates pointed out the enormous potential of chat bots in education. In his opinion, even the most complex and specialized disciplines can be mastered using Chatbots as tutors.

The role of artificial intelligence in education has been repeatedly noted by many researchers, in particular M. Lynch in the work "Seven ways educators can use artificial intelligence" described seven possible options for the use of artificial intelligence in education [7]. In our opinion, the following AI capabilities are most applicable to the development of reflection:

- personalization of the educational process (M. Lynch), which consists in the fact that the speed of studying the necessary material is adapted to the individual capabilities of the student, but, unlike M. Lynch, who believes that the system itself implements this adjustment, we affirm that as reflexive skills are formed, students themselves have an increasingly increasing impact on the system and actively influence the learning process;

- simulation of work in small groups. One of the disadvantages of distance learning is the limited communication with tutors and fellow students, which forces students to "cook in their own juice", not allowing them to develop and improve communicative soft-skills and, in particular, slows down the process of forming reflection. AI will allow you to simulate a communication environment, create conditions for healthy competition to participants in the educational process, which will be a powerful incentive in learning, including the development of reflective skills.

- analysis of own results. Speaking about the use of AI, we mean systems that are not limited to offering standardized tests to students, but those that are able to create and individualize truly non-standard problem situations, the successful resolution of which will require students to mobilize all their intellectual capabilities. And in this case it is not possible to achieve significant results without analyzing the grounds for their own actions.

Currently, there are many effective methods aimed at the formation of reflective abilities and the design of their professional future [10]:

- methodology of volume information modeling (consideration of human activity in space and time, as a result of which a volume model of the life cycle of a future specialist is created);

- a methodology for the analysis of specific situations-cases (analysis of situations in which they learn to avoid mistakes made by other people in practical activities);

- a methodology of functional reflexive text analysis (used for the development of existential reflection, the complexity of which lies in the fact that a person's creative thinking unfolds in the conditions of subjective-semantic awareness of a problem situation, and reflection ensures the development of a person);

- polylogue (each of which deals with determining the subject of discussion);

- inversion (makes it possible to think fantasy, create incredible stories and situations);

- training / video training (the ability to use reflection as a mental tool so that each participant can understand their inner world and the world of others, see their own eyes of other people, see the possibilities of their own changes);

- reflexive (positional) discussion (one group proposes a project, another makes alternative proposals for its optimization, the third gives constructive additions for its development);

- a technique related to the formation of critical thinking, with which a person processes information to solve problems using various forms of activity: identifying and challenging assumptions, checking actual accuracy and logical information, considering the context, exploring the alternative. 
The study was based on Moscow State Regional University. The experiment was attended by graduate students of the Faculty of Physics and Mathematics, the Faculty of Psychology, as well as students of continuing education courses (total 153 people). He was offered work on solving professional case situations using the Chatbots tool.

Before and at the end of the experiment, the participants underwent diagnostics according to the method of O.S. Anisimova in order to determine the dynamics of development of reflection [1].

\section{Results}

We implemented modeling of a multifaceted problem space in the conditions of a specific educational field using the artificial intelligence tool Chatbot system by developing a complex of case situations. Case situations are presented to the student by the Chatbot system depending on the degree of his progress along the trajectory of mastering the educational subject. Figure 1 reflects the actions of the subject, providing a reflective perception of the educational situation, the expansion and deepening of the perception of the problem space.

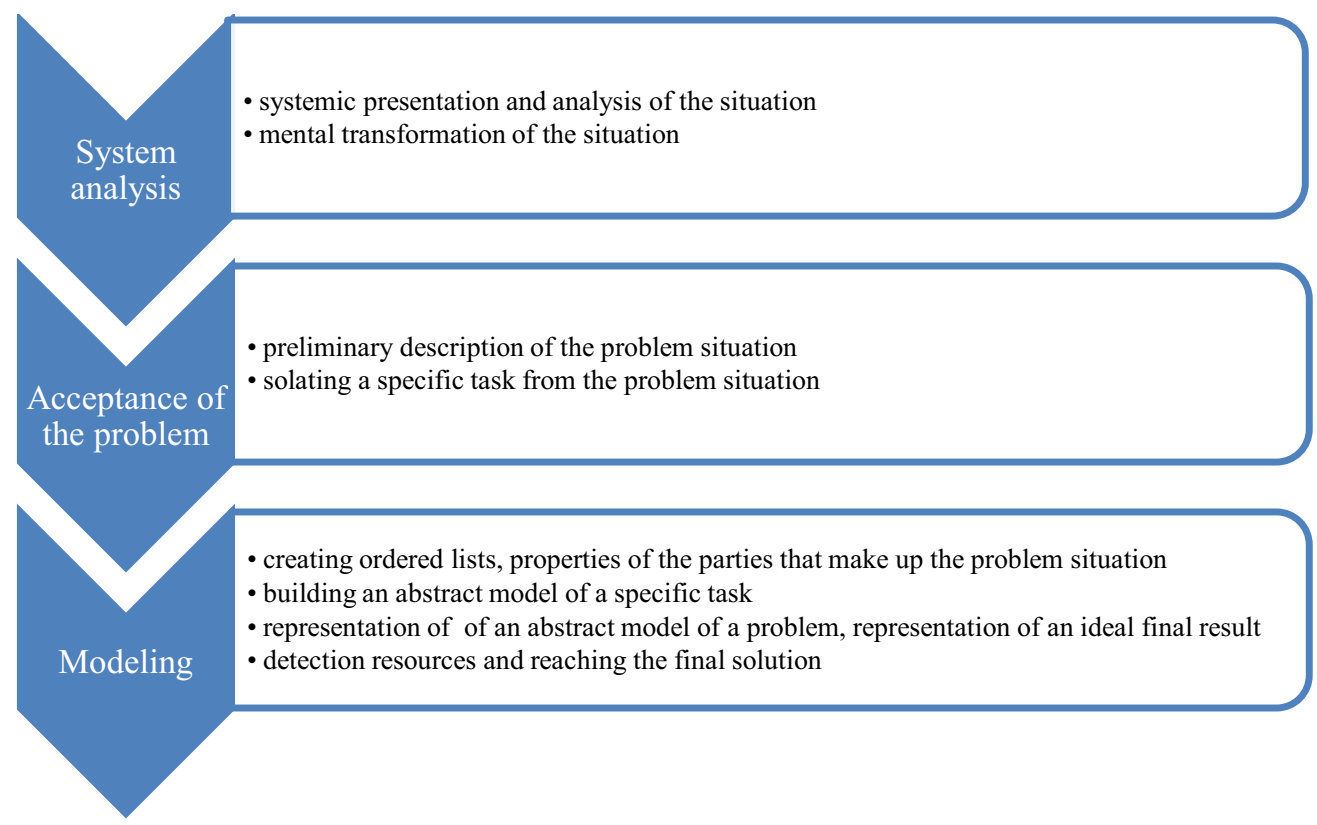

Fig. 1. Reflexive development of a problem space.

Each case-situation was a complex problem, the solution of which can be represented as a sequence of logically interconnected, but at the same time independent tasks, various levels of difficulty and abstractness [5]. Most often, as the initial task, a certain maximally specific and definite situation was proposed, and then the degree of difficulty and abstractness gradually increased. For example, students were asked to formulate on their own a task similar to this, but with some changed conditions; task inverse to this; another task, the inverse of this, but not coinciding with the previous one, a task different from all the previous ones, but having a solution ideologically similar to them, etc. As a final task, it was proposed to summarize as much as possible all previously considered problems and present the most general solution or some formula. A successful transition from one stage to another was regulated by AI and was not possible without an analysis of the grounds for 
their own actions in solving the problem of the previous stage, that is, they required reflective thoughts.

\section{Discussion}

In studying the problem of developing reflection skills using artificial intelligence tools, we encountered technical difficulties that lead to a limitation of the range of case studies offered to students. For a wider implementation of the proposed methodology, improvement of technical capabilities is required, including the expansion of the database by joining modern scientific and methodological centers.

\section{Conclusions}

The study confirmed the hypothesis that, as one of the main tools for the development of reflection of a subject in an educational situation and the reflexive control of his intellectual activity, the use of artificial intelligence is advisable. The Chatbot artificial intelligence tool, functioning as a teacher's assistant, has the ability to flexibly and adaptively respond to the actions of a student while immersed in a problem space when studying and apperceming a case study. Chatbot allows you to simulate a discussion educational environment, taking into account various options, like in real dialogs, to accompany each student user individually, in accordance with his educational level and the chosen pace of learning material.

\section{References}

1. O.S. Anisimov, Acmeological Foundations of the Reflexive Self-Organization of a Teacher: Creativity and Culture of Thinking (Moscow, 1994)

2. A.V. Vetkina, Gazette of Novgorod State University 87(2), 68 (2015)

3. Listen, speak and agree: what are soft skills and how to develop them, https://theoryandpractice.ru/posts/11719-soft-skills/

4. O.L. Chulanova, A.I. Ivonina, J.M. Davletshina, Science 9(1) (2017) https://naukovedenie.ru/PDF/90EVN117.pdf /

5. S.I. Kalinin, A.V. Yastrebov, Selected questions of mathematical analysis and methods of its education: activity aspect (Kirov, Raduga-PRESS Publ., 2015)

6. V.A. Lefevr, Reflection (Moscow, Kogito-Tsentr Publ., 2003)

7. Seven ways educators can use artificial intelligence, https://www.thetechedvocate.org/seven-ways-educators-can-use-artificial-intelligence/

8. I.D. Frumin, M.S. Dobryakova, K.A. Barannikov, I.M. Remorenko, Universal competencies and new literacy: what to teach today to succeed tomorrow. Preliminary findings of the international report on school education transformation trends (Moscow: NIU VShE Publ., 2018)

9. A.S. Patlina, E.D. Popova, Theory and methodology of professional education 2(35), 94 (2017)

10. V.A. Chupina, Gazette of MGOU. Series "Pedagogy" 1, 159 (2012)

11. T.A. Yarkova, I.I. Cherkasova, Tyumen State University Herald.Humanities Research. Humanitates 2(1), 222 (2016) DOI: 10.21684/2411-197X-2016-2-4-222-234

12. http://www.oecd.org/education/Envisioning-the-future-of-education-and-jobs.pdf 